\title{
Presepsin as a diagnostic marker of sepsis in children and adolescents: a systemic review and meta-analysis
}

\author{
Seo Hee Yoon ${ }^{1}$, Eun Hwa Kim², Ha Yan Kim² and Jong Gyun Ahn ${ }^{1 *}$ (D
}

\begin{abstract}
Background: Early diagnosis of sepsis in pediatric patients is vital but remains a major challenge. Previous studies showed that presepsin is potentially a reliable diagnostic biomarker for sepsis in adult and neonates. However, there is no pooled analysis of its efficacy as a diagnostic biomarker for sepsis in children. The aims of the present meta-analysis were to assess the overall diagnostic accuracy of presepsin in pediatric sepsis and compare it to those for C-reactive protein (CRP) and procalcitonin (PCT).

Methods: A systematic literature search was performed in Medline/Pubmed, Embase, the Cochrane Library, and ISI Web of Science to identify relevant studies reporting the diagnostic accuracy of presepsin in patients with pediatric sepsis. Sensitivities and specificities were pooled by bivariate meta-analysis. Heterogeneity was evaluated by $x^{2}$ test.

Results: We identified 129 studies in total. Most were disqualified on the basis of their titles/abstracts and duplication. Four studies were included in the final analysis. They comprised 308 patients aged between 1 mo and $18 \mathrm{y}$. The pooled diagnostic sensitivity and specificity of presepsin were 0.94 (95\% confidence interval [Cl]: 0.74-0.99) and 0.71 (95\% Cl: 0.35-0.92), respectively. The pooled diagnostic odds ratio, positive likelihood ratio (LR), and negative LR of presepsin were 32.87 (95\% Cl: 2.12-510.09), 3.24 (95\% Cl, 1.14-12.38), and 0.08 (95\% Cl, 0.01-0.74), respectively. Heterogeneity was found in both sensitivity $\left(X^{2}=11.17 ; P=0.011\right)$ and specificity $\left(X^{2}=65.78 ; P<0.001\right)$. No threshold effect was identified among the studies $(r=-0.938)$. The pooled sensitivity of presepsin (0.94) was higher than that of CRP (0.51) and PCT (0.76), whereas the overall specificity of presepsin (0.71) was lower than that of CRP (0.81) and PCT (0.76). The AUC of presepsin (0.925) was higher than that of CRP (0.715) and PCT (0.820).
\end{abstract}

Conclusion: Currently available evidence indicates that presepsin has higher sensitivity and diagnostic accuracy, but lower specificity, than PCT or CRP in detecting sepsis in children. However, these results must be carefully interpreted as the number of studies included was small and the studies were statistically heterogeneous.

Keywords: Sepsis, Presepsin, Diagnosis, Meta-analysis, Child, Sensitivity, Specificit

\section{Background}

Sepsis is a life-threatening condition. It is the leading cause of death or morbidity in the pediatric population $[1,2]$. The epidemiology of pediatric sepsis varies [3], but an estimated 1.2 million children worldwide are stricken with it each year [4]. Recent U.S. studies indicated that $>70,000$ children were hospitalized for sepsis at a cost of $\sim \$ 5.0$ billion and a mortality rate of $\leq 20 \%[1,5]$.

\footnotetext{
* Correspondence: JGAHN@yuhs.ac

'Department of Pediatrics, Severance Children's Hospital, Yonsei University College of Medicine, 50-1 Yonsei-ro, Seodaemun-gu, Seoul 03722, Korea Full list of author information is available at the end of the article
}

However, there has been limited research on pediatric sepsis. Management of this condition has often been adapted from guidelines for adult sepsis [6]. It is difficult to define sepsis in the pediatric patient because of agedependent vital signs. Moreover, the seriousness of their condition is often unclear [7]. Sepsis in children is usually diagnosed on the basis of systemic inflammatory response syndrome (SIRS) and a suspected or proven infection [7]. Infection is confirmed when the blood culture/stain/PCR results are positive for a specific pathogen. Sepsis is suspected on the basis of clinical, radiological, or laboratory findings [7-9]. More recently, sepsis was defined as a life-

(C) The Author(s). 2019 Open Access This article is distributed under the terms of the Creative Commons Attribution 4.0 International License (http://creativecommons.org/licenses/by/4.0/), which permits unrestricted use, distribution, and 
threatening organ dysfunction resulting from the deregulation of the host response to infection [10]. Nevertheless, this criterion was formulated for adult sepsis patients. Thus, additional guidelines that reflect age-specific sepsis and stratify its risks for children are necessary [10]. Blood culture remains the gold standard for the confirmation of sepsis $[11,12]$.

On the other hand, blood culture has considerable limitations such as prolonged time-to-result and false negativity [13]. Delays in administration of the appropriate antibiotics are associated with significant increases in mortality and morbidity [14]. Therefore, biomarkers may play a vital role in the timely diagnosis and management of sepsis [15]. The most widely investigated diagnostic biomarkers for pediatric sepsis are $\mathrm{C}$-reactive protein (CRP) and procalcitonin (PCT) [16]. However, CRP alone lacks the specificity to discriminate bacterial, viral and noninfectious inflammatory conditions [17]. The prediction of sepsis is also inaccurate as its sensitivity is low $[17,18]$.

PCT is a promising diagnostic marker for sepsis [11, 19-21] but is inadequate for pediatric sepsis prediction because its sensitivity and specificity are variable $[11,22]$. The large discrepancies between studies in terms of their reported cutoff values limit the utility of these biomarkers in clinical practice [20]. After the onset of infection or inflammation, CRP increases within $4-6 \mathrm{~h}$ and peaks at $36-72 \mathrm{~h}[17,23]$, while PCT rises within $2-4 \mathrm{~h}$ and reaches its maximum at 24-36 h [24-27]. Thus, extra care is necessary when using CRP and PCT as very early biomarkers for sepsis.

CD (cluster of differentiation) 14 is a cell-surface glycoprotein expressed in macrophages, monocytes, dendritic cells, and neutrophils [28]. CD14 is a lipopolysaccharide (LPS) receptor. It transfer the LPS signal from bacteria via Toll-like receptor-4 [29], triggers the release of proinflammatory cytokines, and activates a systematic inflammatory response [30]. Presepsin consists of the Nterminal $13 \mathrm{kDa}$ fragment of the CD14 protein [31]. Several recent studies presented presepsin as a promising diagnostic biomarker for adult sepsis [32-35]. A current systematic review reported that presepsin had high sensitivity and specificity in predicting neonatal sepsis [36]. Presepsin levels increase within $2 \mathrm{~h}$ and peak at $3 \mathrm{~h}$ after the onset of infection [24]. Serum presepsin can be measured easily and rapidly [37]. Therefore, presepsin could be a useful biomarker for the early diagnosis of sepsis. Several clinical studies [38-41] proposed the diagnostic value of presepsin in pediatric sepsis. However, there is no published meta-analysis of its diagnostic efficacy in pediatric sepsis patients.

Therefore, we conducted a systematic review and metaanalysis to assess the diagnostic value of presepsin in pediatric sepsis and compare it with other biomarkers.

\section{Methods}

This meta-analysis was conducted and reported in compliance with the Preferred Reporting Items for Systematic Reviews and Meta-Analyses Statement (PRISMA) [42].

\section{Search strategy}

Medline/Pubmed, Embase, the Cochrane Library, and ISI Web of Science were searched for studies reporting the performance of presepsin in the diagnosis of pediatric sepsis. The search algorithms used for each database are shown in Additional file 1. The search was executed on February 13, 2019. Reference lists were also screened for pertinent articles and all languages were included in the search.

\section{Study selection}

Two reviewers (SHY) and (JGY) independently evaluated the eligibility of the studies. In cases of disagreement, a third reviewer (HYK) was also consulted. No date restrictions were applied to the study search. Studies included were those reporting on the efficacy of serum presepsin in the diagnosis of pediatric sepsis. The pediatric age range was defined as $>4$ wks weeks and $<18 \mathrm{y}$. All article titles and abstracts were screened for relevance and eligibility.

Studies evaluating the accuracy of presepsin in the diagnosis of pediatric sepsis and those providing sufficient data to extract a $2 \times 2$ contingency table were included. The presence of infection was defined as microbiologically confirmed (smear microscopy, culture method, or PCR) or suspected as probable according to a clinical record review [11]. Studies addressing catheter-related bloodstream infections (CRBSI) were eligible as CRSBI is a bacteremia originating from an intravascular device [43, 44]. Full texts were retrieved for all articles meeting the aforementioned criteria.

Articles were excluded if they did not address sepsis or assess presepsin. Studies that did not separately consider pediatric patients were also omitted. Reviews, letters, editorials, expert opinions, and animal experiments were also ruled out. Finally, reports with overlapping data or with insufficient data to calculate presepsin sensitivity or specificity were eliminated.

\section{Data extraction}

The following variables were independently extracted by two authors (SHY and JGA): first author, publication year, country, type of study, clinical setting, age range at diagnosis, sample size, number of patients and controls, sample type, cutoff value, inclusion and exclusion criteria, diagnostic references, and presepsin assay methods. Authors were contacted by e-mail and additional data were requested in the event of information gaps. For studies consisting of multiple groups and/or different 
backgrounds, the analysis of each group was treated as a single study.

\section{Quality assessment}

The methodological quality of each study was tested with the Quality Assessment Tool for Diagnostic Accuracy Studies (QUADAS-2 score) [45]. This evaluation includes the following bias risk assessment domains: patient selection, index test, reference standard, flow and timing, sources of variation (applicability), and reporting quality.

\section{Statistical analysis}

Accuracy data (true positive, false positive, false negative, and true negative) were extracted for each study. A $2 \times 2$ contingency table was constructed to calculate sensitivity, specificity, positive and negative likelihood ratios (LR), and diagnostic odds ratio (DOR) with their corresponding 95\% confidence intervals $(95 \% \mathrm{CI})$. A value of 0.5 was added to all cells for studies with zero values to correct for continuity. Results were evaluated by forest plots. Heterogeneity of sensitivity and specificity was evaluated by a $X^{2}$ test. $P<0.10$ indicated significant heterogeneity. In this case, a bivariate random effects model was adopted [46, 47].

The threshold effect is a major source of heterogeneity in meta-analyses of diagnostic tests [48]. The studies included used different cutoff values for presepsin in sepsis diagnosis. Therefore, a threshold effect is anticipated. Therefore, Spearman's correlation coefficient (r) was calculated. $\mathrm{R} \geq 0.6$ indicated a threshold effect [49].

Summary sensitivity and specificity were calculated with a bivariate model and a hierarchical summary receiver operating characteristic (HSROC) model [48].

R v. 3.5.2 (http://www.R-project.org) was used for the statistical and meta-analyses. Publication bias was measured with funnel plots. Egger's test evaluated funnel plot asymmetry [50]. The trim-and-fill method corrected for any funnel plot asymmetry resulting from publication bias [51].

\section{Results}

One hundred and twenty-nine published studies were gleaned from our electronic database search. Of these, 113 were excluded after title and abstract screening and the remaining 15 were subjected to full text reviews (Fig. 1). Of these, seven had insufficient data to construct a $2 \times 2$ contingency table and five did not include children or adolescents.

Three studies met our criteria. Of these, one presented two sets of results from different patients/controls. Thus, it was included as a separate study. Thus, four studies were included in our qualitative assessment and meta- analysis [38-40] (Fig. 1). The characteristics of these studies are listed in Table 1.

All eligible studies were published between 2016 and 2018. One was conducted in Turkey [38], one in Egypt [39], and two in Slovakia [40]. Three of them were prospective studies and one was retrospective. Three hundred and eight patients were included in the four studies. Of the 207 (67.2\%) patients in the control group, $127(61.4 \%)$ were categorized as non-sepsis patients and $80(38.6 \%)$ as healthy volunteers. There were 101 patients with sepsis (32.8\%).

Patient populations were heterogeneous (Table 1). Three studies included patients with hematological malignancy (HM), and one included patients with CRBSI. Of the three studies with HM patients, one included those on chemotherapy with febrile neutropenia [39] and the other two included those presenting with fever, hypothermia, chills, or other putative signs of sepsis [40].

Two studies identified sepsis patients by positive bacterial cultures [39, 40]. One study [38] defined sepsis patients according to the criteria of the Infectious Diseases Society of America (IDSA) consensus conference (2009) [44]. Another study [40] designated sepsis patients based on the modified International Pediatric Sepsis Consensus Conference definition (IPSCC) (2005) [7].

One study used serum [38], one used plasma [39], and the other used unspecified blood samples [40] to test for sepsis. Three studies used PATHFAST [39, 40], and another used ELISA [38] to assay for presepsin. The presepsin cutoff values for sepsis detection ranged from 240 to $1014 \mathrm{pg} \mathrm{mL}^{-1}$.

\section{Quality assessment}

The output of the QUADAS-2 tool is summarized in Fig. 2. Two studies evaluated the optimal cutoff value to calculate sensitivity and specificity instead of using the predefined value scored 'high risk' in the index test domain. In terms of the patient selection domain, the risk of bias was low in most studies as they clearly defined their exclusion criteria. Two studies did not include all patients in their analyses and were scored 'unclear' in the patient flow and timing domains. All studies had low risk in the reference standard domain as they used positive blood culture, the guidelines of the IDSA consensus conference [44], and the IPSCC definition [7] to diagnose sepsis.

Most of the studies scored 'unclear' in terms of the patient selection domain as the majority of the enrolled patients had HM. One study scored 'unclear' in the reference standard domain as it defined the disease condition as CRBSI which limited its applicability.

\section{Meta-analysis for diagnostic accuracy}

Descriptive statistics of the diagnostic accuracy of presepsin are presented in the form of a forest plot in Fig. 3. 


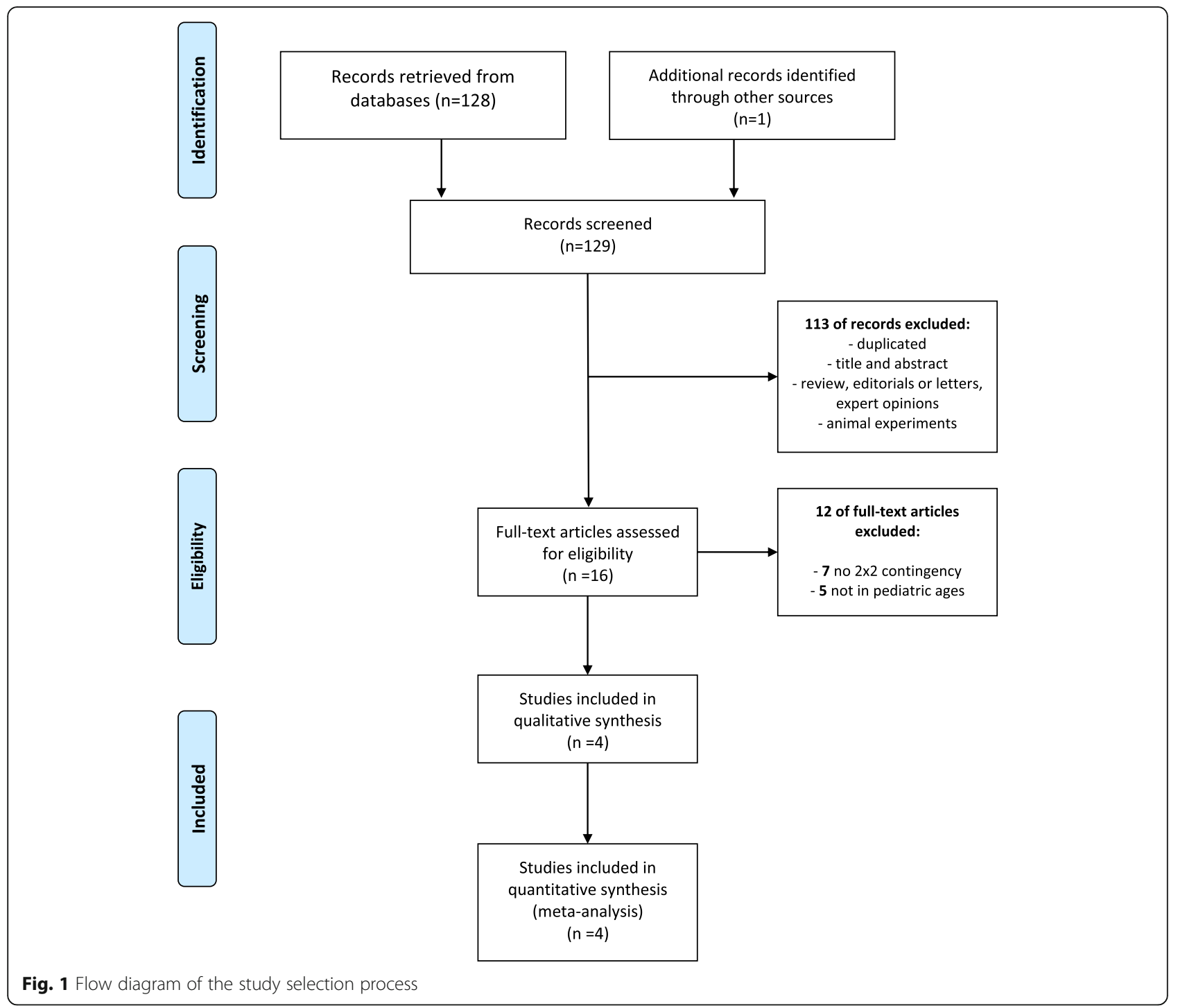

Significant heterogeneity between studies was noted in terms of sensitivity $\left(\chi^{2}=11.17 ; P=0.0108\right)$ and specificity $\left(X^{2}=65.78 ; P<0.0001\right)$. Spearman's correlation coefficient (r) was -0.938 (95\% CI; -0.999 to 0.234$)$. Thus, there was no threshold effect (Additional file 2).

Summary estimates of sensitivity, specificity, positive LR, negative LR, and DOR were calculated with a bivariate random effects model (Table 2). The overall sensitivity was $0.94(95 \% \mathrm{CI} ; 0.74-0.99)$ and the specificity was 0.71 (95\% CI; 0.35-0.92). The area under the [HSROC] curve (AUC) was 0.925 (Fig. 4). Therefore, presepsin had a high diagnostic accuracy for pediatric sepsis.

An asymmetric funnel plot and Egger's test $(P=$ 0.0001 ) revealed publication bias among the studies (Additional file 3). The trim-and-fill method was applied for bias correction and showed $\log \mathrm{DOR}=2.39$ for presepsin corresponding to a pooled DOR $=10.91$ (Fig. 5).
The presepsin cutoff value for detecting pediatric sepsis varies, ranging from 240 to $1014 \mathrm{pg} / \mathrm{ml}$. Mean cutoff value was $635.8 \mathrm{pg} / \mathrm{ml}$. Due to the varied cutoff values between studies, we conducted subgroup analysis using a cutoff value of $650 \mathrm{pg} / \mathrm{ml}$. Two studies [38, 39] featured cutoff values higher than $650 \mathrm{pg} / \mathrm{ml}$ and the other two studies [40] had cutoff values lower than $650 \mathrm{pg} / \mathrm{ml}$. We found higher pooled sensitivity $(0.84$ vs. 0.99$)$ and specificity $(0.42$ vs. 0.90$)$ in the studies where cutoff value was greater than $650 \mathrm{pg} / \mathrm{ml}$. This cutoff value featured higher diagnostic accuracy as well (AUC 0.827 vs. 0.983) (Table 3, Additional file 4).

\section{Comparison of the performances of presepsin, CRP, and PCT}

Three studies compared presepsin with CRP and PCT. Two of these defined the patient by positive blood 
Table 1 Summary of the included studies

\begin{tabular}{|c|c|c|c|c|c|c|c|c|c|c|c|c|}
\hline No & $\begin{array}{l}\text { Author } \\
\text { (Year) }\end{array}$ & Country & $\begin{array}{l}\text { Type of } \\
\text { study }\end{array}$ & $\begin{array}{l}\text { Age } \\
\text { (range) }\end{array}$ & $\begin{array}{l}\text { Sample } \\
\text { Size (all) }\end{array}$ & $\begin{array}{l}\text { Patients/ } \\
\text { control } \\
(n)\end{array}$ & $\begin{array}{l}\text { Cutoff } \\
(\mathrm{ng} \\
\left.\mathrm{mL}^{-1}\right)\end{array}$ & Sample & $\begin{array}{l}\text { Inclusion } \\
\text { criteria }\end{array}$ & Exclusion & References & Assay \\
\hline 1 & $\begin{array}{l}\text { Tanır } \\
\text { Basaranoglu } \\
2018\end{array}$ & Turkey & Prospective & $\begin{array}{l}1 \mathrm{mo}- \\
18 \mathrm{y}\end{array}$ & 138 & $\begin{array}{l}58 \\
\text { sepsis/ } \\
80 \\
\text { (healthy } \\
\text { controls) }\end{array}$ & 990 & serum & $\begin{array}{l}1 \text { mo-18 y, } \\
\text { clinical signs } \\
\text { of CRBSI }\end{array}$ & $\begin{array}{l}\text { received } \\
\text { antibiotics } \\
\text { within the } 24 \mathrm{~h} \\
\text { of presentation } \\
\text { with fever }\end{array}$ & $\begin{array}{l}2009 \text { IDSA } \\
\text { guideline }\end{array}$ & ELISA \\
\hline 2 & $\begin{array}{l}\text { Baraka } \\
2018\end{array}$ & Egypt & $\begin{array}{l}\text { Case- } \\
\text { control }\end{array}$ & $2-15 y$ & 60 & $\begin{array}{l}18 \\
\text { sepsis/ } \\
42 \text { (non- } \\
\text { sepsis } \\
\text { patients) }\end{array}$ & 1014 & plasma & $\begin{array}{l}<16 \text { y, } \\
\text { pediatric } \\
\text { patients with } \\
\text { HM, during } \\
\text { episodes of } \\
\text { fever and } \\
\text { neutropenia } \\
\text { after } \\
\text { receiving CTx }\end{array}$ & $\begin{array}{l}\text { age }>16 \text { y, non- } \\
\text { HM pediatric } \\
\text { patients, not on } \\
\text { chemotherapy }\end{array}$ & $\begin{array}{l}\text { blood } \\
\text { culture }\end{array}$ & PATHFAST \\
\hline 3 & $\begin{array}{l}\text { Plesko } \\
2016-1\end{array}$ & Slovakia & Prospective & $\begin{array}{l}1.5- \\
18.9 y\end{array}$ & 55 & $\begin{array}{l}12 \\
\text { sepsis/ } \\
43 \text { (non- } \\
\text { sepsis } \\
\text { patients) }\end{array}$ & 240 & unspecified & $\begin{array}{l}<18.9 \text { y, } \\
\text { pediatric } \\
\text { patients with } \\
\text { HM, the } \\
\text { presence of } \\
\text { fever, } \\
\text { hypothermia, } \\
\text { chills, or } \\
\text { another sign } \\
\text { of possible } \\
\text { sepsis }\end{array}$ & $\begin{array}{l}\text { Febrile episodes } \\
\text { thought to be } \\
\text { an adverse } \\
\text { effect of } C T x \text {, } \\
\text { not having } \\
\text { blood culture } \\
\text { drawn, patients } \\
\text { with proven } \\
\text { non-bacterial } \\
\text { infection }\end{array}$ & $\begin{array}{l}\text { blood } \\
\text { culture }\end{array}$ & PATHFAST \\
\hline 3 & $\begin{array}{l}\text { Plesko } \\
2016-2\end{array}$ & Slovakia & Prospective & $\begin{array}{l}1.5- \\
18.9 y\end{array}$ & 55 & $\begin{array}{l}13 \\
\text { sepsis/ } \\
42 \text { (non- } \\
\text { sepsis } \\
\text { patients) }\end{array}$ & 299 & unspecified & $\begin{array}{l}<18.9 \text { y, } \\
\text { pediatric } \\
\text { patients with } \\
\text { HM, the } \\
\text { presence of } \\
\text { fever, } \\
\text { hypothermia, } \\
\text { chills, or } \\
\text { another sign } \\
\text { of possible } \\
\text { sepsis }\end{array}$ & $\begin{array}{l}\text { Febrile episodes } \\
\text { thought to be } \\
\text { an adverse } \\
\text { effect of } C T x \text {, } \\
\text { not having } \\
\text { blood culture } \\
\text { drawn, patients } \\
\text { with proven } \\
\text { non-bacterial } \\
\text { infection }\end{array}$ & $\begin{array}{l}\text { modified } \\
\text { IPSCC } \\
\text { definition } \\
(2005)\end{array}$ & PATHFAST \\
\hline
\end{tabular}

CRBSI catheter-related blood stream infection, CTx chemotherapy, HM hematologic malignancy, IDSA Infectious Diseases Society of America, IPSCC International Pediatric Sepsis Consensus Conference

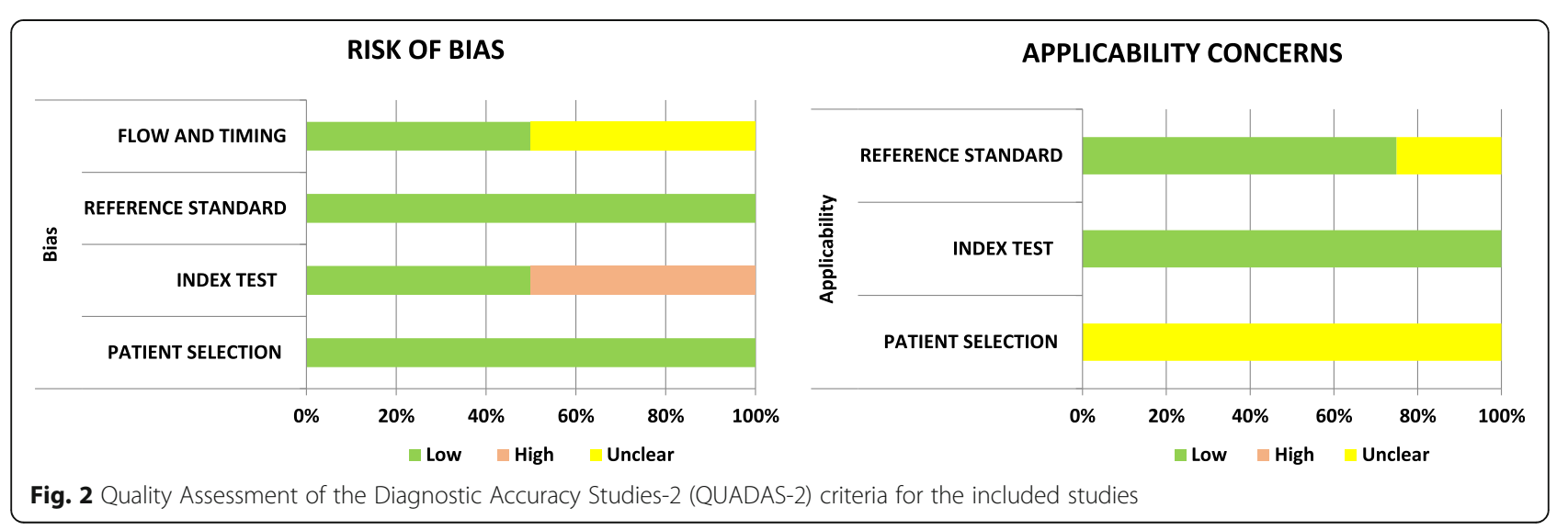




\begin{tabular}{|c|c|c|c|c|c|c|c|c|}
\hline Author(s) and Year & TP & FP & FN & TN & Sensitivity $(95 \% \mathrm{Cl})$ & & Specificity (95\% Cl) & \\
\hline \multicolumn{9}{|l|}{ Presepsin } \\
\hline Plesko 2016-1 & 10 & 31 & 2 & 12 & $0.81[0.54,0.94]$ & $\longrightarrow$ & $0.28[0.17,0.43]$ & $\rightarrow$ \\
\hline Plesko 2016-2 & 11 & 18 & 2 & 24 & $0.82[0.56,0.94]$ & $\longrightarrow$ & $0.57[0.42,0.71]$ & $\because$ \\
\hline Tanir Basaranoglu 2018 & 58 & 5 & 0 & 75 & $0.99[0.92,1.00]$ & $\rightarrow$ & $0.93[0.86,0.97]$ & $\rightarrow$ \\
\hline Baraka 2018 & 18 & 6 & 0 & 36 & $0.97[0.79,1.00]$ & $\longrightarrow$ & $0.85[0.71,0.93]$ & $\rightarrow$ \\
\hline Summary & & & & & $0.94[0.74,0.99]$ & $\longrightarrow$ & $0.71[0.35,0.92]$ & $\longrightarrow$ \\
\hline \multicolumn{9}{|l|}{ CRP } \\
\hline Plesko 2016-1 & 6 & 2 & 16 & 45 & $0.28[0.14,0.49]$ & $\rightarrow$ & $0.95[0.85,0.98]$ & $\rightarrow$ \\
\hline Plesko 2016-2 & 8 & 15 & 8 & 38 & $0.50[0.29,0.72]$ & $\longrightarrow$ & $0.71[0.58,0.82]$ & $\rightarrow$ \\
\hline Baraka 2018 & 14 & 14 & 4 & 28 & $0.76[0.54,0.90]$ & $\longrightarrow$ & $0.66[0.51,0.79]$ & $\rightarrow$ \\
\hline Summary & & & & & $0.51[0.24,0.78]$ & $\longrightarrow$ & $0.81[0.53,0.94]$ & $\longrightarrow$ \\
\hline \multicolumn{9}{|l|}{ РСT } \\
\hline Plesko 2016-1 & 17 & 14 & 4 & 30 & $0.80[0.59,0.91]$ & $\longrightarrow$ & $0.68[0.53,0.80]$ & $\rightarrow-$ \\
\hline Plesko 2016-2 & 10 & 10 & 5 & 40 & $0.66[0.42,0.84]$ & $\longrightarrow$ & $0.79[0.67,0.88]$ & $\rightarrow$ \\
\hline Baraka 2018 & 18 & 8 & 0 & 34 & $0.97[0.79,1.00]$ & $\rightarrow$ & $0.80[0.66,0.89]$ & $\rightarrow$ \\
\hline Summary & & & & & $0.76[0.59,0.88]$ & $\rightarrow$ & $0.76[0.67,0.83]$ & $\rightarrow$ \\
\hline Total summary & & & & & $0.79[0.60,0.90]$ & $\because$ & $0.75[0.61,0.86]$ & $\div$ \\
\hline
\end{tabular}

Fig. 3 Forest plots of the sensitivity and specificity of presepsin, C-reactive protein (CRP), and procacitonin (PCT) for the diagnosis of pediatric sepsis

culture $[38,40]$ and one used the modified IPSCC definition [40]. Descriptive statistics of the diagnostic accuracy of CRP and PCT for sepsis detection are presented in a forest plot (Fig. 3) and summarized in Table 2.

The pooled sensitivity of presepsin was higher than those of CRP and PCT [presepsin: 0.94 (95\% CI: 0.740.99); CRP: 0.51 (95\% CI: 0.24-0.78); PCT: 0.76 (95\% CI: $0.59-0.88)]$. In contrast, the pooled specificity of presepsin was lower than that of CRP and PCT [presepsin: 0.71
(95\% CI: 0.35-0.92); CRP: 0.81 (95\% CI: 0.53-0.94); PCT: 0.76 (95\% CI: 0.67-0.83)]. The AUC of presepsin (0.925) was higher than that of CRP (0.715) and PCT (0.830) (Fig. 4) Thus, presepsin had a higher diagnostic performance than CRP or PCT. Threshold effects could not be calculated for CRT and PCT as there were too few studies involving them. Funnel plots of the studies including CRP and PCT indicated no publication bias (Additional file 3).

Table 2 Summary estimates of the diagnostic accuracy of presepsin, C-reactive protein, procalcitonin to diagnose pediatric sepsis

\begin{tabular}{|c|c|c|c|c|c|}
\hline Author(s) and year & $\begin{array}{l}\text { Sensitivity } \\
(95 \% \mathrm{Cl})\end{array}$ & $\begin{array}{l}\text { Specificity } \\
(95 \% \text { Cl) }\end{array}$ & $\begin{array}{l}\text { Positive LR } \\
(95 \% \mathrm{Cl})\end{array}$ & $\begin{array}{l}\text { Negative LR } \\
(95 \% \mathrm{Cl})\end{array}$ & $\begin{array}{l}\text { DOR } \\
(95 \% \mathrm{Cl})\end{array}$ \\
\hline \multicolumn{6}{|l|}{ Presepsin } \\
\hline Plesko 2016-1 & $0.81[0.54,0.94]$ & $0.28[0.17,0.43]$ & $1.13[0.82,1.56]$ & $0.68[0.20,2.27]$ & $1.67[0.36,7.67]$ \\
\hline Plesko 2016-2 & $0.82[0.56,0.94]$ & $0.57[0.42,0.71]$ & $1.91[1.25,2.91]$ & $0.31[0.10,0.99]$ & $6.09[1.37,27.17]$ \\
\hline Tanir Basaranoglu 2017 & $0.99[0.92,1.00]$ & $0.93[0.86,0.97]$ & $14.60[6.51,32.73]$ & $0.01[0.001,0.14]$ & $1606.09[87.05,29,633.96]$ \\
\hline Baraka 2018 & $0.97[0.79,1.00]$ & $0.85[0.71,0.93]$ & $6.44[3.16,13.13]$ & $0.03[0.002,0.48]$ & $207.77[11.09,3892.29]$ \\
\hline Bivariate summary estimates ( $95 \% \mathrm{Cl}$ ) & $0.94[0.74,0.99]$ & $0.71[0.35,0.92]$ & $3.24[1.14,12.38]$ & $0.08[0.01,0.74]$ & $32.87[2.12,510.09]$ \\
\hline \multicolumn{6}{|l|}{ CRP } \\
\hline Plesko 2016-1 & $0.28[0.14,0.49]$ & $0.95[0.85,0.98]$ & $5.43[1.38,21.38]$ & $0.76[0.58,0.99]$ & $7.17[1.50,34.24]$ \\
\hline Plesko 2016-2 & $0.50[0.29,0.72]$ & $0.71[0.58,0.82]$ & $1.74[0.92,3.29]$ & $0.70[0.42,1.16]$ & $2.48[0.81,7.60]$ \\
\hline Baraka 2018 & $0.76[0.54,0.90]$ & $0.66[0.51,0.79]$ & $2.26[1.39,3.69]$ & $0.36[0.16,0.82]$ & $6.33[1.85,21.72]$ \\
\hline Bivariate summary estimates ( $95 \% \mathrm{Cl}$ ) & $0.51[0.24,0.78]$ & $0.81[0.53,0.94]$ & $2.68[0.51,13.00]$ & $0.60[0.23,1.43]$ & $4.63[2.16,9.95]$ \\
\hline \multicolumn{6}{|l|}{ PCT } \\
\hline Plesko 2016-1 & $0.80[0.59,0.91]$ & $0.68[0.53,0.80]$ & $2.47[1.54,3.97]$ & $0.30[0.13,0.71]$ & $8.18[2.44,27.43]$ \\
\hline Plesko 2016-2 & $0.66[0.42,0.84]$ & $0.79[0.67,0.88]$ & $3.19[1.67,6.08]$ & $0.43[0.22,0.86]$ & $7.36[2.14,25.32]$ \\
\hline Baraka 2018 & $0.97[0.79,1.00]$ & $0.80[0.66,0.89]$ & $4.93[2.69,9.04]$ & $0.03[0.002,0.51]$ & $150.18[8.20,2750.01]$ \\
\hline Bivariate summary estimates (95\% Cl) & $0.76[0.59,0.88]$ & $0.76[0.67,0.83]$ & $3.17[1.79,5.18]$ & $0.32[0.61,0.14]$ & $11.88[3.49,40.47]$ \\
\hline Bivariate summary estimates (95\% Cl) (Total) & $0.79[0.60,0.90]$ & $0.75[0.61,0.86]$ & $3.16[1.54,6.43]$ & $0.28[0.66,0.12]$ & $10.76[4.31,26.83]$ \\
\hline
\end{tabular}




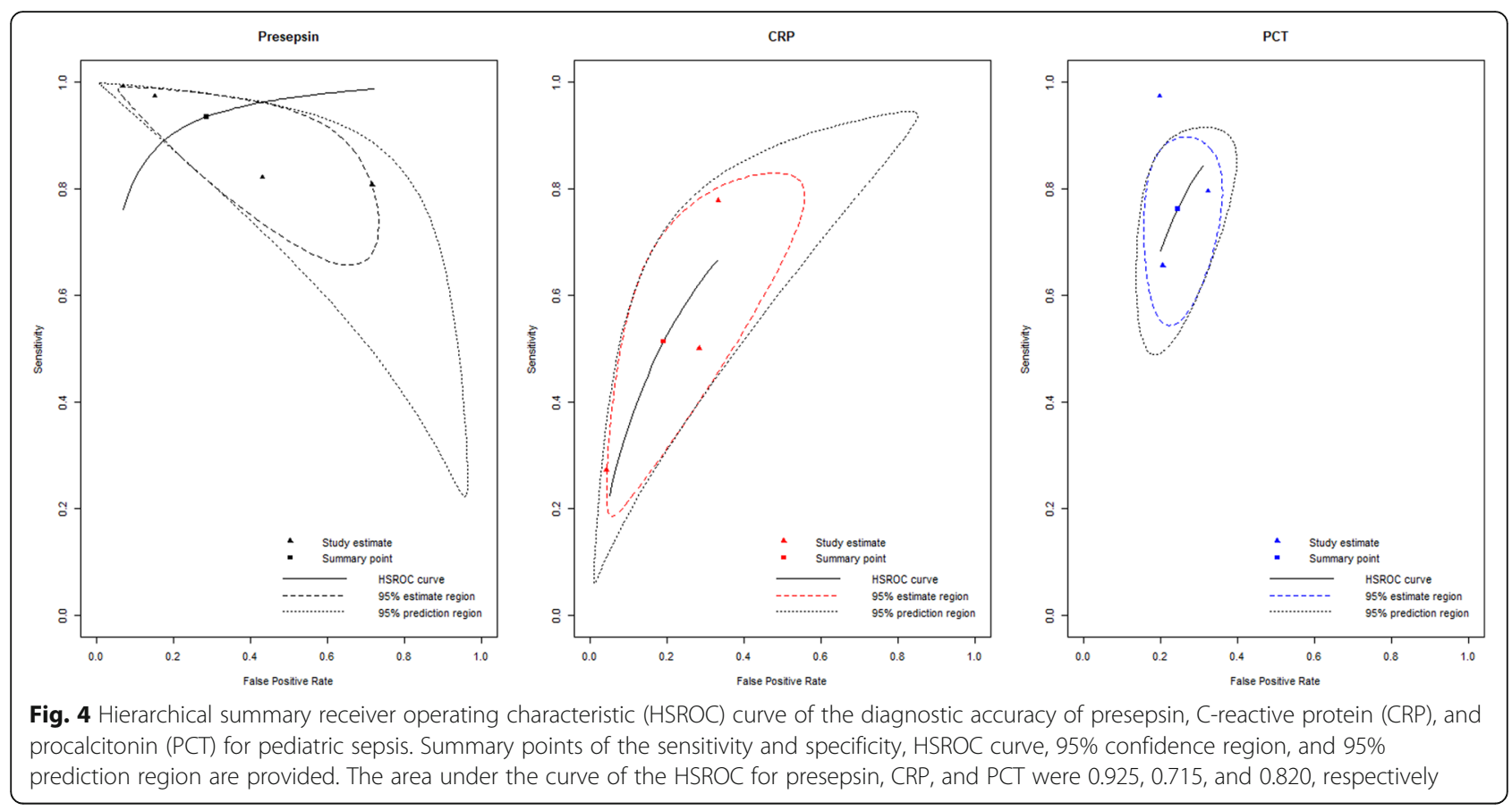

\section{Discussion}

The present study summarizes the overall performance of presepsin in the diagnosis of pediatric sepsis and is based on currently available literature. To the best of our knowledge, this is the first systematic review and meta-analysis to evaluate the diagnostic value of presepsin for pediatric sepsis (not including neonates). Presepsin had high sensitivity and moderate specificity. Presepsin also displayed high diagnostic performance in predicting pediatric sepsis. Thus,

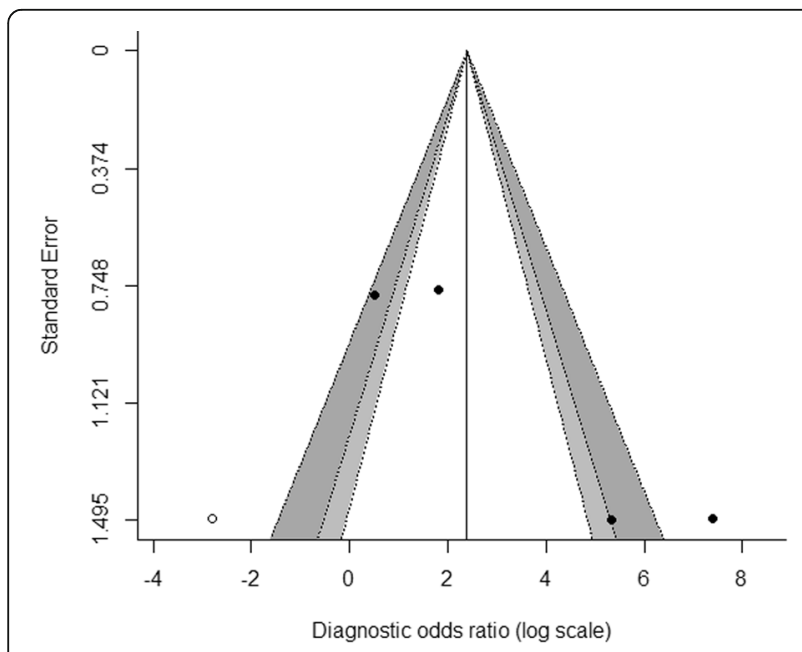

Fig. 5 Trim-and-fill funnel plot of the log of diagnostic odds ratio (DOR) of presepsin to diagnose pediatric sepsis. The $x$-axis represents the study result $[\log (\mathrm{DOR})]$. The $y$-axis represents the study precision [the standard error of log (DOR)]. Each filled dot represents one study presepsin may be a useful diagnostic biomarker for pediatric sepsis.

To date, several meta-analyses of the diagnostic accuracy of presepsin in adult sepsis have been published. They reported pooled sensitivities ranging from 0.78 0.86 , pooled specificities ranging from $0.73-0.83$, positive likelihood ratios ranging from $3.40-4.63$, negative likelihood ratios ranging from $0.18-0.22$, DOR ranging from 14.25-22.0, and AUC ranging from 0.86-0.89 [32-35, 52, 53]. Two recent meta-analyses indicated pooled presepsin sensitivities and specificities each in the range $0.9-0.91$ for the diagnosis of neonatal sepsis $[36,54]$. The DOR was in the range 120.94-170.28 and the AUC was in the range 0.968-0.975 [36, 54]. The present study showed higher sensitivity and similar specificity of presepsin for the diagnosis of pediatric sepsis relative to those for adult sepsis. For the diagnosis of pediatric sepsis, however, presepsin had similar sensitivity and lower specificity compared to neonatal sepsis analysis. As it has high sensitivity, presepsin may be very useful for the exclusion of sepsis in pediatric patients when the level of this biomarker is normal or lower than the cutoff value. Nevertheless, the specificity of presepsin is only moderate. Consequently, it may be necessary to diagnose sepsis by correlating it with clinical symptoms as false positives could occur.

\section{Presepsin level according to the etiologies of sepsis}

Acute-phase reactants, such as CRP, PCT, and presepsin are a class of serum proteins that change in response to 
Table 3 Diagnostic accuracy of presepsin according to the cut off value

\begin{tabular}{|c|c|c|c|c|c|c|c|}
\hline & $\begin{array}{l}\text { Number of } \\
\text { studies }\end{array}$ & $\begin{array}{l}\text { Sensitivity (95\% } \\
\text { Cl) }\end{array}$ & $\begin{array}{l}\text { Specificity (95\% } \\
\text { Cl) }\end{array}$ & $\begin{array}{l}\text { Positive LR (95\% } \\
\text { Cl) }\end{array}$ & $\begin{array}{l}\text { Negative LR (95\% } \\
\mathrm{Cl})\end{array}$ & DOR $(95 \% \mathrm{Cl})$ & AUC \\
\hline $\begin{array}{l}\text { Cutoff } \leq 650 \mathrm{pg} / \\
\mathrm{ml}\end{array}$ & 2 & $0.84[0.64,0.94]$ & $0.42[0.18,0.71]$ & $1.45[0.78,3.24]$ & $0.38[0.08,2.00]$ & $3.81[1.03,14.04]$ & 0.827 \\
\hline $\begin{array}{l}\text { Cutoff }>650 \mathrm{pg} / \\
\mathrm{ml}\end{array}$ & 2 & $0.99[0.88,1.00]$ & $0.90[0.78,0.96]$ & $9.9[4.00,25.00]$ & $0.01[0.001,0.15]$ & $\begin{array}{l}580.75[73.53 \\
4586.94]\end{array}$ & 0.983 \\
\hline
\end{tabular}

$C$ confidence interval, $L R$ likelihood ratio, $D O R$ diagnostic odds ratio, $A U C$ area under the receiver operating characteristic curve

inflammation from infections, surgery, trauma, autoimmune disorders, and malignancy $[15,55,56]$. The level of acute phase reactants usually reflects the presence and degree of an inflammatory process so they are thought to have the potential capacities in early diagnosis by differentiating sepsis from non-infectious systemic inflammation, as prognostic implications, and in antibiotic guidance strategies [15, 57-59]. However, it is believed that the level of acute phase reactant is not specific to any particular disease, nor can they precisely distinguish infection from other etiologies of acute and chronic inflammation [56, 60, 61]. Furthermore, there are still not enough studies to show whether the level of acute phase reactants would change according to the specific microorganism $[15,61,62]$.

In our review, two studies reported the level of presepin according to the causing organisms. One study [38] showed that median presepsin values were similar within the groups of microorganisms; the median presepsin value was $1668 \mathrm{pg} / \mathrm{ml}$ (range: 1048-2935) for gram-positive bacteremia patients, $1756 \mathrm{pg} / \mathrm{ml}$ (range: 1103-2033) for gram-negative bacteremia patients, and $1406 \mathrm{pg} / \mathrm{ml}$ (range: 1348-1566) for candidemia patients.

The other study [40] reported that the mean log value of presepsin was $2.47(\mathrm{SD} 0.13)(\mathrm{pg} / \mathrm{ml})$ for gram positive bacteremia patients and 2.64 (SD 0.29) (pg/ml) for gram negative bacteremia patients with no statistical difference $(P=0.237)$. However, we could not conduct subgroup analysis due to insufficient data.

\section{Cut off values of presepsin for diagnosing sepsis}

Cutoff value of presepsin for diagnosing sepsis varies according to the different reference tests, controls, and clinical settings. In recent adult meta-analysis, cutoff values ranged from 317 to $849 \mathrm{pg} / \mathrm{ml}$ and the optimal cut off value was $600-650 \mathrm{pg} / \mathrm{ml}$ [35]. The authors found similar sensitivity $(0.85$ vs. 0.84$)$ but lower pooled specificity in the cutoff values greater than $700 \mathrm{pg} / \mathrm{ml}$ studies, compared to values smaller than $700 \mathrm{pg} / \mathrm{ml}$ studies $(0.59$ vs. 0.80) [35]. In recent neonatal meta-analysis, presepsin cutoff value ranged from 304.5 to $885.0 \mathrm{pg} / \mathrm{ml}$ and when using a cutoff value $<600 \mathrm{ng} / \mathrm{L}$, sensitivity was 0.93 , with a specificity of 0.81 and AUC 0.8195; using a cut-off value of $>600 \mathrm{ng} / \mathrm{L}$ resulted in sensitivity of 0.87 and specificity of 0.97 , with higher diagnostic accuracy
(AUC 0.976) [54]. However, the other neonatal metaanalysis reported that its diagnostic efficacy was maximized (sensitivity 0.91, specificity 0.97, AUC 0.99) when using a presepsin cutoff value ranging from 650 to $850 \mathrm{pg} / \mathrm{ml}$ [36].

In our study, the presepsin cutoff value for detecting pediatric sepsis varies, ranging from 240 to $1014 \mathrm{pg} / \mathrm{ml}$. We found higher pooled sensitivity, specificity and diagnostic accuracy in the cutoff value greater than $650 \mathrm{pg} /$ $\mathrm{ml}$. However, a small sample size and heterogeneous characteristics of included studies are limitations disallowing the application of these results from clinical practice at this stage.

\section{Comparison of CRP, and PCT as diagnostic biomarkers for sepsis}

CRP and PCT are the most commonly used diagnostic biomarker for pediatric sepsis and their diagnostic accuracies have been extensively studied [16, 25]. Several clinical studies showed that PCT has higher diagnostic accuracy than CRP in the differentiation of sepsis and SIRS (PCT: $\mathrm{AUC}=0.71-0.99 ; \quad \mathrm{CRP}: \quad \mathrm{AUC}=0.54-0.65$ ) $[63,64]$. A recent meta-analysis investigated the diagnostic accuracy of PCT in the distinction of sepsis from SIRS. PCT had good sensitivity (pooled, 0.78 ) and poor specificity (pooled, 0.57) at a cutoff value of $<2.0 \mathrm{ng} \mathrm{mL}^{-1}$ in pediatric patients older than neonates [11].

Several head-to-head comparisons were made between presepsin and PCT or CRP in adult patients. A recent adult patient meta-analysis disclosed no statistically significant difference in the diagnostic accuracy of sepsis between presepsin and CRP (presepsin: $\mathrm{AUC}=0.85$; CRP: AUC $=0.85$ ) or between presepsin and PCT (presepsin: $A U C=0.87$; PCT: $A U C=0.86$ ) [35]. For studies conducted on patients in intensive care units, the pooled sensitivity of presepsin was higher than that of PCT (0.88 vs. 0.75$)$, but lower than that of РCT (0.58 vs. 0.75$)$ [35]. Another meta-analysis compared the diagnostic value of PCT with that of presepsin for sepsis in critically ill adult patients. The pooled sensitivities $(0.84$ for presepsin and 0.8 for $\mathrm{PCT}$ ) and specificities (0.73 for presepsin and 0.75 for PCT) did not significantly differ between the two biomarkers [65].

Presepsin may be the most accurate biomarker of neonatal sepsis. One study showed that presepsin had higher 
AUC than CRP (0.975 vs. 0.858 ) and PCT (0.959 vs. 0.783 ) [36]. In the present study, the overall sensitivity of presepsin was higher than that of CRP (0.94 vs. 0.51) and PCT (0.94 vs. 0.76$)$. However, the overall specificity of presepsin was lower than that of CRP (0.71 vs. 0.81) and PCT (0.71 vs. 0.76). Moreover, the AUC of presepsin was higher than that of CRP (0.925 vs. 0.715$)$ and PCT (0.925 vs. 0.830$)$. These results suggest that the overall diagnostic performance of presepsin is greater than that of CRP and PCT. Furthermore, presepsin levels increase earlier in response to sepsis than either CRP or PCT [24]. Thus, presepsin may be promising as a sensitive biomarker for the early diagnosis of sepsis in pediatric patients.

To the best of our knowledge, this systematic review and meta-analysis is the first to evaluate the performance of presepsin as a diagnostic biomarker of sepsis in pediatric patients (excluding neonates) and to compare it with PCT and CRP. Nevertheless, our study had several limitations. First, only four publications were included as there was relatively little currently available data for pediatric sepsis patients. Second, differences in the reference standards, control group definitions, and specimen types in the included studies are possible sources of heterogeneity. Moreover, we could not conduct a subgroup analysis as the number of included studies was very small. Third, the included studies comprised mainly enrolled HM pediatric patients. Three of four studies included in the meta-analysis were conducted in pediatric patients with hematologic malignancies. Thus, this is a major limitation of the study, and the conclusions cannot be generalized for all pediatric populations. Therefore, a more prospective clinical study with a larger sample size is necessary to compensate for the aforementioned deficiencies.

\section{Conclusions}

Presepsin showed higher sensitivity and accuracy but relatively lower specificity for the diagnosis of pediatric sepsis than either PCT or CRP.

Owing to the small number and heterogeneity of the included studies, however, the foregoing results should be carefully interpreted and applied. Future clinical trials are required to validate and determine the optimal presepsin cutoff for the diagnosis of sepsis in children.

\section{Additional files}

Additional file 1: Search Strategy. (DOCX $16 \mathrm{~kb}$ )

Additional file 2: Inter-study heterogeneity and threshold effect. (DOCX $19 \mathrm{~kb}$ )

Additional file 3: Funnel plots for the assessment of publication bias. (DOCX $127 \mathrm{~kb}$ )
Additional file 4: Inter-study heterogeneity (subgroup analysis according to the cut-off value). (DOCX $19 \mathrm{~kb}$ )

\section{Abbreviations}

AUC: Area under the receiver operating characteristic curve; CD: Cluster of differentiation; Cl: Confidence interval; CRP: C-reactive protein; DOR: Diagnostic odds ratio; HM: Hematological malignancy;

HSROC: Hierarchical summary receiver operating characteristic; IDSA: Infectious Diseases Society of America; LPS: Lipopolysaccharide; LR: Likelihood ratio; PCT: Procalcitonin; PLR: Positive likelihood ratio; PRISMA: Preferred Reporting Items for Systematic Reviews and Meta-Analyses Statement; QUADAS: Quality Assessment of Diagnostic Accuracy Studies; SIRS: Systemic inflammatory response syndrome

\section{Acknowledgements}

Not applicable.

\section{Authors' contributions}

SHY designed the search strategy, performed the literature search and review, extracted the data, and wrote the manuscript. JGA conceived the study, reviewed the protocol, participated in the literature review, and drafted the manuscript. EHK and HYK performed the statistical analysis and participated in the literature review, study design, and study coordination. All authors read and approved the final manuscript.

\section{Funding}

The present study was supported by a 2018 grant from the Korean Society of Pediatric Infectious Diseases. The funder did not participate in study design, data collection, data analysis, decision to publish, or manuscript preparation.

\section{Availability of data and materials}

The data used in the present study are appropriately cited.

\section{Ethics approval and consent to participate}

No institutional review board approval or ethics statement was required as the present meta-analysis was retrospective.

\section{Consent for publication}

Not applicable.

\section{Competing interests}

The authors declare that they have no competing interests.

\section{Author details}

${ }^{1}$ Department of Pediatrics, Severance Children's Hospital, Yonsei University College of Medicine, 50-1 Yonsei-ro, Seodaemun-gu, Seoul 03722, Korea.

${ }^{2}$ Biostatistics Collaboration Unit, Department of Biomedical Systems Informatics, Yonsei University College of Medicine, Seoul, Korea.

Received: 3 June 2019 Accepted: 23 August 2019

Published online: 30 August 2019

\section{References}

1. Ruth A, McCracken CE, Fortenberry JD, Hall M, Simon HK, Hebbar KB. Pediatric severe sepsis: current trends and outcomes from the pediatric health information systems database. Pediatr Crit Care Med. 2014;15(9): 828-38.

2. Hartman ME, Linde-Zwirble WT, Angus DC, Watson RS. Trends in the epidemiology of pediatric severe sepsis*. Pediatr Crit Care Med. 2013;14(7): 686-93.

3. Kawasaki T. Update on pediatric sepsis: a review. J Intensive Care. 2017; 5(1):47.

4. Fleischmann-Struzek C, Goldfarb DM, Schlattmann P, Schlapbach LJ, Reinhart K, Kissoon N. The global burden of paediatric and neonatal sepsis: a systematic review. Lancet Respir Med. 2018;6(3):223-30.

5. Balamuth F, Weiss SL, Neuman MI, Scott H, Brady PW, Paul R, Farris RW, McClead R, Hayes K, Gaieski D, et al. Pediatric severe sepsis in U.S. children's hospitals. Pediatr Crit Care Med. 2014;15(9):798-805. 
6. Mathias B, Mira JC, Larson SD. Pediatric sepsis. Curr Opin Pediatr. 2016; 28(3):380-7.

7. Goldstein B, Giroir B, Randolph A. International pediatric sepsis consensus conference: definitions for sepsis and organ dysfunction in pediatrics. Pediatr Crit Care Med. 2005;6(1):2-8.

8. Levy MM, Fink MP, Marshall JC, Abraham E, Angus D, Cook D, Cohen J, Opal SM, Vincent JL, Ramsay G. 2001 SCCM/ESICM/ACCP/ATS/SIS international Sepsis definitions conference. Crit Care Med. 2003;31(4):1250-6.

9. Reinhart K, Bauer M, Riedemann NC, Hartog CS. New approaches to sepsis: molecular diagnostics and biomarkers. Clin Microbiol Rev. 2012;25(4):609-34.

10. Singer M, Deutschman CS, Seymour CW, Shankar-Hari M, Annane D, Bauer M, Bellomo R, Bernard GR, Chiche JD, Coopersmith CM, et al. The third international consensus definitions for Sepsis and septic shock (Sepsis-3). Jama. 2016;315(8):801-10.

11. Pontrelli G, De Crescenzo F, Buzzetti R, Jenkner A, Balduzzi S, Calo Carducc F, Amodio D, De Luca M, Chiurchiu S, Davies EH, et al. Accuracy of serum procalcitonin for the diagnosis of sepsis in neonates and children with systemic inflammatory syndrome: a meta-analysis. BMC Infect Dis. 2017; 17(1):302.

12. Liesenfeld O, Lehman L, Hunfeld KP, Kost G. Molecular diagnosis of sepsis: new aspects and recent developments. Eur J Microbiol Immunol. 2014;4(1):1-25.

13. Carrigan SD, Scott G, Tabrizian M. Toward resolving the challenges of sepsis diagnosis. Clin Chem. 2004;50(8):1301-14.

14. Plunkett A, Tong J. Sepsis in children. Bmj. 2015;350:h3017.

15. Markanday A. Acute Phase Reactants in Infections: Evidence-Based Review and a Guide for Clinicians. Open Forum Infectious Dis. 2015;2(3):ofv098.

16. Henriquez-Camacho C, Losa J. Biomarkers for sepsis. Biomed Res Int. 2014; 2014:547818.

17. Standage SW, Wong HR. Biomarkers for pediatric sepsis and septic shock. Expert Rev Anti-Infect Ther. 2011;9(1):71-9.

18. Sanders S, Barnett A, Correa-Velez I, Coulthard M, Doust J. Systematic review of the diagnostic accuracy of C-reactive protein to detect bacterial infection in nonhospitalized infants and children with fever. J Pediatr. 2008;153(4): $570-4$.

19. Rowland T, Hilliard H, Barlow G. Procalcitonin: potential role in diagnosis and management of sepsis. Adv Clin Chem. 2015;68:71-86.

20. van Rossum AM, Wulkan RW, Oudesluys-Murphy AM. Procalcitonin as an early marker of infection in neonates and children. Lancet Infect Dis. 2004; 4(10):620-30.

21. Lin SG, Hou TY, Huang DH, He SY, Lin YD, Zhang LY, Hsieh PS. Role of procalcitonin in the diagnosis of severe infection in pediatric patients with fever and neutropenia--a systemic review and meta-analysis. Pediatr Infect Dis J. 2012;31(10):e182-8.

22. Yo C-H, Hsieh P-S, Lee S-H, Wu J-Y, Chang S-S, Tasi K-C, Lee C-C. Comparison of the test characteristics of Procalcitonin to C-reactive protein and leukocytosis for the detection of serious bacterial infections in children presenting with fever without source: a systematic review and metaanalysis. Ann Emerg Med. 2012;60(5):591-600.

23. Volanakis JE. Human C-reactive protein: expression, structure, and function. Mol Immunol. 2001;38(2-3):189-97.

24. Okamura Y, Yokoi H. Development of a point-of-care assay system for measurement of presepsin (sCD14-ST). Clin Chim Acta. 2011;412(23-24): 2157-61.

25. Lanziotti VS, Póvoa P, Soares M, Silva JRLE, Barbosa AP, Salluh JIF. Use of biomarkers in pediatric sepsis: literature review. Revista Brasileira de terapia intensiva. 2016;28(4):472-82.

26. Meisner M. Update on procalcitonin measurements. Ann Lab Med. 2014; 34(4):263-73.

27. Becker KL, Snider R, Nylen ES. Procalcitonin in sepsis and systemic inflammation: a harmful biomarker and a therapeutic target. Br J Pharmacol. 2010;159(2):253-64.

28. Płóciennikowska A, Hromada-Judycka A, Borzęcka K, Kwiatkowska K. Cooperation of TLR4 and raft proteins in LPS-induced pro-inflammatory signaling. Cell Mol Life Sci. 2015;72(3):557-81.

29. Gong XW. Jiang Y: [structure, function and modulation of actin-related protein 2/3 complex]. Sheng Li Ke Xue Jin Zhan. 2004;35(4):306-10.

30. Zou Q, Wen W, Zhang XC. Presepsin as a novel sepsis biomarker. World J Emerg Med. 2014;5(1):16-9.

31. Mussap M, Noto A, Fravega M, Fanos V. Soluble CD14 subtype presepsin (SCD14-ST) and lipopolysaccharide binding protein (LBP) in neonatal sepsis: new clinical and analytical perspectives for two old biomarkers. J Matern Fetal Neonatal Med. 2011;24(Suppl 2):12-4.

32. Wu J, Hu L, Zhang G, Wu F, He T. Accuracy of Presepsin in Sepsis diagnosis: a systematic review and meta-analysis. PLoS One. 2015;10(7):e0133057.

33. Zheng Z, Jiang L, Ye L, Gao Y, Tang L, Zhang M. The accuracy of presepsin for the diagnosis of sepsis from SIRS: a systematic review and meta-analysis. Ann Intensive Care. 2015;5(1):48.

34. Tong X, Cao Y, Yu M, Han C. Presepsin as a diagnostic marker for sepsis: evidence from a bivariate meta-analysis. Ther Clin Risk Manag. 2015;11: 1027-33.

35. Wu CC, Lan HM, Han ST, Chaou CH, Yeh CF, Liu SH, Li CH, Blaney GN 3rd, Liu ZY, Chen KF. Comparison of diagnostic accuracy in sepsis between presepsin, procalcitonin, and C-reactive protein: a systematic review and meta-analysis. Ann Intensive Care. 2017;7(1):91.

36. Bellos I, Fitrou G, Pergialiotis V, Thomakos N, Perrea DN, Daskalakis G. The diagnostic accuracy of presepsin in neonatal sepsis: a meta-analysis. Eur J Pediatr. 2018;177(5):625-32.

37. Chenevier-Gobeaux C, Borderie D, Weiss N, Mallet-Coste T, Claessens Y-E. Presepsin (sCD14-ST), an innate immune response marker in sepsis. Clin Chim Acta. 2015;450:97-103.

38. Tanir Basaranoglu S, Karadag-Oncel E, Aykac K, Ozsurekci Y, Aycan AE, Cengiz AB, Kara A, Ceyhan M. Presepsin: a new marker of catheter related blood stream infections in pediatric patients. J Infect Chemother. 2018;24(1):25-30.

39. Baraka A, Zakaria M. Presepsin as a diagnostic marker of bacterial infections in febrile neutropenic pediatric patients with hematological malignancies. Int J Hematol. 2018;108(2):184-91.

40. Plesko M, Suvada J, Makohusova M, Waczulikova I, Behulova D, Vasilenkova A, Vargova M, Stecova A, Kaiserova E, Kolenova A. The role of CRP, PCT, IL-6 and presepsin in early diagnosis of bacterial infectious complications in paediatric haemato-oncological patients. Neoplasma. 2016;63(5):752-60.

41. Olad E, Sedighi I, Mehrvar A, Tashvighi M, Fallahazad V, Hedayatiasl A, Esfahani H. Presepsin (scd14) as a marker of serious bacterial infections in chemotherapy induced severe neutropenia. Iran J Pediatr. 2014;24(6): $715-22$.

42. Moher D, Liberati A, Tetzlaff J, Altman DG. Preferred reporting items for systematic reviews and meta-analyses: the PRISMA statement. J Clin Epidemiol. 2009;62(10):1006-12.

43. Kitanovski L, Jazbec J, Hojker S, Derganc M. Diagnostic accuracy of lipopolysaccharide-binding protein for predicting bacteremia/clinical sepsis in children with febrile neutropenia: comparison with interleukin6, procalcitonin, and C-reactive protein. Support Care Cancer. 2014;22(1): 269-77.

44. Mermel LA, Rijnders BJA, Allon M, Craven DE, Flynn P, O'Grady NP, Raad II, Sherertz RJ, Warren DK, Bouza E. Clinical practice guidelines for the diagnosis and Management of Intravascular Catheter-Related Infection: 2009 update by the Infectious Diseases Society of America. Clin Infect Dis. 2009; 49(1):1-45.

45. Whiting PF, Rutjes AWS, Westwood ME, Mallett S, Deeks JJ, Reitsma JB, Leeflang MMG, Sterne JAC, Bossuyt PMM, Group tQ. QUADAS-2: a revised tool for the quality assessment of diagnostic accuracy studies. Ann Intern Med. 2011;155(8):529-36.

46. Higgins JPT, Thompson SG, Deeks JJ, Altman DG. Measuring inconsistency in meta-analyses. BMJ. 2003;327(7414):557-60.

47. Higgins JP, Thompson SG. Quantifying heterogeneity in a meta-analysis. Stat Med. 2002;21(11):1539-58.

48. Reitsma JB, Glas AS, Rutjes AWS, Scholten RJPM, Bossuyt PM, Zwinderman AH. Bivariate analysis of sensitivity and specificity produces informative summary measures in diagnostic reviews. J Clin Epidemiol. 2005;58(10):982-90.

49. Glas AS, Lijmer JG, Prins MH, Bonsel GJ, Bossuyt PM. The diagnostic odds ratio: a single indicator of test performance. J Clin Epidemiol. 2003;56(11): 1129-35.

50. Egger M, Smith GD, Schneider M, Minder C. Bias in meta-analysis detected by a simple, graphical test. BMJ. 1997;315(7109):629-34.

51. Duval S, Tweedie R. Trim and fill: a simple funnel-plot-based method of testing and adjusting for publication bias in meta-analysis. Biometrics. 2000; 56(2):455-63.

52. Zhang X, Liu D, Liu YN, Wang R, Xie LX. The accuracy of presepsin (sCD14-ST) for the diagnosis of sepsis in adults: a meta-analysis. Crit Care. 2015;19:323. 
53. Zhang J, Hu ZD, Song J, Shao J. Diagnostic value of Presepsin for Sepsis: a systematic review and meta-analysis. Medicine (Baltimore). 2015;94(47):e2158.

54. Parri N, Trippella G, Lisi C, De Martino M, Galli L, Chiappini E. Accuracy of presepsin in neonatal sepsis: systematic review and meta-analysis. Expert Rev Anti-Infect Ther. 2019;17(4):223-32.

55. Dowton $\mathrm{SB}$, Colten HR. Acute phase reactants in inflammation and infection. Semin Hematol. 1988;25(2):84-90.

56. Gabay C, Kushner I. Acute-phase proteins and other systemic responses to inflammation. N Engl J Med. 1999;340(6):448-54.

57. Schuetz P, Wirz Y, Sager R, Christ-Crain M, Stolz D, Tamm M, Bouadma L, Luyt CE, Wolff M, Chastre J, et al. Effect of procalcitonin-guided antibiotic treatment on mortality in acute respiratory infections: a patient level metaanalysis. Lancet Infect Dis. 2018;18(1):95-107.

58. Daniels LM, Tosh PK, Fiala JA, Schleck CD, Mandrekar JN, Beckman TJ. Extremely elevated erythrocyte sedimentation rates: associations with Patients' diagnoses, demographic characteristics, and comorbidities. Mayo Clin Proc. 2017;92(11):1636-43.

59. Kruger S, Ewig S, Giersdorf S, Hartmann O, Suttorp N, Welte T. Cardiovascular and inflammatory biomarkers to predict short- and longterm survival in community-acquired pneumonia: results from the German competence network, CAPNETZ. Am J Respir Crit Care Med. 2010;182(11): 1426-34.

60. Gulhar R, Jialal I. Physiology, acute phase reactants. In: StatPearls. Treasure Island: StatPearls Publishing; 2019.

61. Kushner I. Acute phase reactants. Wolters Kluwer; 2019. https://www. uptodate.com/contents/acute-phase-reactants. [cited 10th July 2019].

62. Schrodl W, Buchler R, Wendler S, Reinhold P, Muckova P, Reindl J, Rhode H. Acute phase proteins as promising biomarkers: perspectives and limitations for human and veterinary medicine. Proteomics Clin Appl. 2016;10(11): 1077-92.

63. Arkader R, Troster EJ, Lopes MR, Junior RR, Carcillo JA, Leone C, Okay TS. Procalcitonin does discriminate between sepsis and systemic inflammatory response syndrome. Arch Dis Child. 2006;91(2):117-20.

64. Simon L, Saint-Louis P, Amre DK, Lacroix J, Gauvin F. Procalcitonin and Creactive protein as markers of bacterial infection in critically ill children at onset of systemic inflammatory response syndrome. Pediatr Crit Care Med. 2008;9(4):407-13

65. Kondo Y, Umemura Y, Hayashida K, Hara Y, Aihara M, Yamakawa K. Diagnostic value of procalcitonin and presepsin for sepsis in critically ill adult patients: a systematic review and meta-analysis. J Intensive Care. 2019;7:22.

\section{Publisher's Note}

Springer Nature remains neutral with regard to jurisdictional claims in published maps and institutional affiliations.

Ready to submit your research? Choose BMC and benefit from:

- fast, convenient online submission

- thorough peer review by experienced researchers in your field

- rapid publication on acceptance

- support for research data, including large and complex data types

- gold Open Access which fosters wider collaboration and increased citations

- maximum visibility for your research: over $100 \mathrm{M}$ website views per year

At BMC, research is always in progress.

Learn more biomedcentral.com/submissions 